\title{
A CULTURA DO MILHO: NITROGENIO E INOCULAÇÃO COM BACTÉRIAS PROMOTORAS DE CRESCIMENTO
}

AUTORES: Freddy Zambrano Gavilanes ${ }^{1}$

Diva Souza Andrade ${ }^{2}$

Helder Rodrigues Silva ${ }^{3}$

Roberto Bravo Zamora ${ }^{4}$

Carlos Cedeño Palacios 5

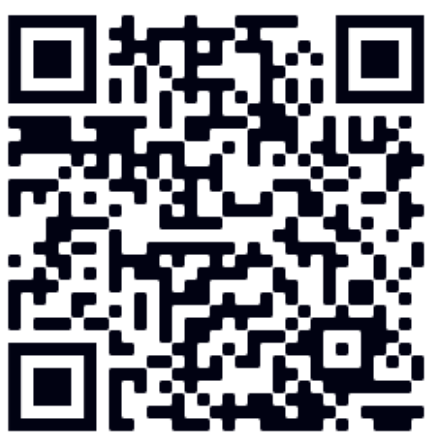

DIRECCIÓN PARA CORRESPONDENCIA:freddyzg86@hotmail.com

Fecha de recepción: 18/08/2019

Fecha de aceptación: 26/11/2019

RESUMEN

$\mathrm{O}$ milho (Zea mays L.) é uma das culturas mais importantes do mundo. O nitrogênio (N) é considerado un dos nutrientes maíz requerido pela cultura do milho, estando relacionado com a sua produção, entretanto, sujeito a perdas no solo por lixiviação, escoamento superficial e volatilização, provocando prejuízos ambientais. A aplicação de bactérias promotoras do crescimento de plantas (BPCPs), para o incremento da produção agrícola é una das alternativas mais importantes para depender menos dos fertilizantes químicos. As BPCPs estimulam a fixação biológica do nitrogênio (FBN). Algumas espécies do gênero Azospirillum têm essa capacidade além de produzir hormônios promotores de crescimento favorecendo a cultura do milho e outras Poáceas

PALABRAS CLAVE: Zea mays L.; Fixação Biológica do Nitrogênio; Fertilizantes; Inoculantes.

\section{MAIZE CROP: NITROGEN AND INOCULATION WITH GROWTH PROMOTING BACTERIA}

\section{ABSTRACT}

Maize (Zea mays L.) is one of the most important crops in the world. Nitrogen (N) is considered one of the nutrients most required by maize crop, being related to its production, however, subject

\footnotetext{
${ }^{1}$ Universidad Técnica de Manabí, UTM. Docente de la Facultad de Ingeniería Agronómica. Universidad Técnica de Manabí. Ecuador.

${ }^{2}$ Instituto Agronômico do Paraná, IAPAR. Professora, Pesquisadora. Instituto Agronômico do Paraná, Londrina, Paraná, Brasil.

${ }^{3}$ Universidade Estadual de Londrina, UEL. Programa de Pós Graduação em Bioenergia. Pós Doutorando, Universidade Estadual de Londrina, Londrina, Paraná, Brasil.

${ }^{4}$ Universidad Técnica de Manabí, UTM. Docente de la Facultad de Ingeniería Agronómica. Universidad Técnica de Manabí. Ecuador.

${ }^{5}$ niversidad Técnica de Manabí, UTM. Docente de la Facultad de Ciencias Matemáticas, Físicas y Químicas, Departamento de Procesos Químicos. Universidad Técnica de Manabí. Ecuador.
} 
Freddy Zambrano Gavilanes, Diva Souza Andrade, Helder Rodrigues Silva...

to soil losses due to leaching, surface runoff and volatilization, causing environmental damages. The application of plant growth promoting bacteria (BPCPs) to increase agricultural production is one of the most important alternatives for relying less on chemical fertilizers. BPCPs stimulate biological nitrogen fixation (BNF). Some species of the genus Azospirillum have this capacity in addition to producing growth promoting hormones favoring the cultivation of maize and other Poace.

KEYWORDS: Zea mays L.; Biological Fixation of Nitrogen; Fertilizers; Inoculants

\section{INTRODUCCIÓN}

O milho (Zea mays L.) é uma das culturas mais importantes do mundo e no Brasil é a segunda cultura de maior importância depois da soja, sendo utilizado o seu grão principalmente como base alimentar da população e componente básico em rações alimentícias de aves e suínos. Assim também, tem sido usado para a fabricação do etanol para biocombustíveis.

Diversos fatores influenciam o desenvolvimento e desempenho produtivo do milho, destacando-se as condições edafoclimáticas, o material genético, o manejo da cultura, e disponibilização de macro e micronutrientes, dos quais o Nitrogênio $(\mathrm{N})$ é o nutriente mais limitante. As fontes nitrogenadas mais empregadas são a ureia e o sulfato de amônio, provenientes de derivados do petróleo, que acarretam danos ambientais, sujeitos a perdas de nitrogênio por lixiviação, escoamento superficial, volatilização da amônia e desnitrificação, além de custos de produção para a cultura.

Diferentes trabalhos estão sendo realizados para diminuir o uso de fertilizantes convencionais e torná-los solúveis e disponíveis para os vegetais, sobressaindo a utilização de microrganismos como as Bactérias Promotoras do Crescimento de Plantas (BPCPs), uma das alternativas mais relevantes. Algumas BPCPs, com capacidade de estimular o crescimento da parte aérea e radicular das plantas, proporcionar tolerância a estresses e controle biológico. Assim também, algumas como as diazotróficas, promovem a fixação biológica do nitrogênio (FBN), que é um processo de redução do nitrogênio atmosférico $\left(\mathrm{N}_{2}\right)$ a amônio, sendo uma opção apropriada sob os aspectos econômicos e ambientais, reduzindo em grande medida o uso de fertilizantes nitrogenados sintéticos.

Atualmente estão sendo comercializados inoculantes a partir de bactérias do gênero Azospirillum, para poáceas como o milho e trigo, assim como rizóbios para fabáceas como soja e feijão, incrementando a produtividade dessas culturas.

Assim a presente revisão de literatura tem por objetivo principal descrever aspectos da cultura do milho e importância do nitrogênio e de bactérias promotoras de crescimento.

\section{DESARROLLO}

O milho (Zea mays L.) tem sido a cultura mais importante os povos ancestrais (Dressler, 1953). Registros arqueológicos mostram uma domesticação na América Central há cerca de 5800 anos A.E.C. e 3900 anos A.E.C. na América do Sul, a partir de um segmento do gene que codifica a álcool Desidrogenase 2 (Adh2), amplificada e sequenciada extraído de espécimes arqueológicas e contemporâneas de milho, mostrando que havia uma diversidade nestes momentos do passado (Mangelsdorf, 1974). 
O pool genético do milho data de milhões de anos, e de raças domésticas originárias de várias populações selvagens ancestrais (Goloubinoff, Pääbo, \& Wilson, 1993). O milho representa uma das principais espécies domesticadas usadas na agricultura moderna, originada a partir de uma ou mais espécies do teosinte (Zea mays parviglumis e Zea mays mexicana) (Freitas, 2002).

Na classificação botânica, o milho pertence à ordem Poales, família Poaceae, tribo Maydeae, gênero Zea e espécie Zea mays L. O caráter monoico e a sua morfologia característica resultam da supressão, condensação e multiplicação de várias partes da anatomia básica das gramíneas. Os aspectos vegetativos e reprodutivos da planta podem ser modificados através da interação com os fatores ambientais que afetam o controle da ontogenia do desenvolvimento. Como resultado geral da seleção natural e da domesticação obteve-se uma planta anual, robusta e ereta, com um a quatro metros de altura, "construída" para a produção de grãos (Magalhães, 2002).

A sua grande adaptabilidade, representada por variados genótipos, permite o seu cultivo desde o Equador até regiões temperadas e desde o nível do mar até altitudes superiores a 3600 metros, encontrando-se, assim, em climas tropicais, subtropicais e temperados (Barros \& Calado, 2014).

O milho é cultivado em regiões cuja precipitação varia de 300 a $5.000 \mathrm{~mm}$ anuais, sendo a quantidade de água consumida durante o seu ciclo em torno de $600 \mathrm{~mm}$ (Magalhães \& Durães, 2006).

É uma planta anual, de crescimento determinado, com um extenso sistema radicular fibroso, com folhas alternadas em ambos os lados do colmo, pubescentes na parte adaxial e glabrosas na parte abaxial. É uma espécie de polinização cruzada, com as flores separadas sobre as plantas, sendo estas do sexo feminino (espiga) e masculino (pendão). O grão se desenvolve na espiga, cada espiga tem cerca de 300 a 1000 grãos, pesando entre 190 e 300 g por 1000 grãos, em um número variável de linhas (12 a 16); com metabolismo fotossintético C4 (Bolaños \& Edmeades, 1993; Kole, 2007).

\section{IMPORTÂNCIA DA CULTURA DO MILHO}

O milho encontra-se entre as mais importantes culturas do mundo com aproximadamente 960 milhões de toneladas anuais. Estados Unidos, China, Brasil e Argentina são os maiores produtores, representando $70 \%$ da produção mundial (Peixoto, 2014). No Brasil é a segunda maior cultura produzida depois da soja, cultivada em duas safras por ano.

Segundo o levantamento da CONAB (2017), no Brasil o total da área consolidada plantada com milho atingiu 17.391,3 milhões de hectares com produção total de 96.026,2 milhões de toneladas, com produtividade variável nos diferentes Estados e regiões.

No Brasil, esse grão é significativo no domínio econômico e social, sendo usado na alimentação humana e animal, além de servir como matéria prima diversificada para diferentes processos industriais (Santos, Viana, Jesus, Baldani, \& Ferreira, 2015).

O milho tem assumido importante papel socioeconômico no Brasil, colocando-se em posição de relevância no que se refere ao valor da produção agropecuária, área plantada e volume produzido, em especial nas regiões Sul, Sudeste e Centro-Oeste (Severino, Carvalho, \& Christoffoleti, 2006).

\section{MELHORAMENTO GENÉTICO DA CULTURA DO MILHO}

A diversidade genética existente no milho permite o seu cultivo nos mais diversos ambientes, cresce a latitude $58^{\circ} \mathrm{N}$ no Canadá e na ex-União Soviética até latitude $40^{\circ} \mathrm{S}$ no hemisfério sul. Também é cultivado em regiões abaixo do nível do mar, na planície do mar Cáspio e em altitudes 
Freddy Zambrano Gavilanes, Diva Souza Andrade, Helder Rodrigues Silva...

de mais de 4000 m nos Andes Peruanos. É uma espécie diploide com um número de cromossomas de $2 n=2 x=20$, e tem um tamanho de genoma moderado de cerca $2400 \mathrm{Mb}$ (Kole, 2007).

O germoplasma de milho é constituído por raças crioulas (locais), populares adaptadas e materiais exóticos introduzidos, sendo caracterizado por uma ampla variabilidade genética. De maneira geral, as populações crioulas são menos produtivas que os genótipos comerciais. Entretanto, essas populações são importantes por constituírem fonte de variabilidade genética que pode ser explorada na busca por genes tolerantes e/ou resistentes a fatores bióticos e abióticos (Araújo \& Nass, 2002).

O desenvolvimento do milho híbrido ocurreu a partir da visão de Darwin sobre a fertilização cruzada aumentando o vigor. Os princípios de Darwin de seleção natural e artificial para adaptação durante o crescimento de milho de polinização aberta no cinturão do milho (Corn Belt) nos Estados Unidos, seguido do objetivo das empresas de sementes híbridas de fornecer híbridos mais amplamente adaptados (mais resistentes a intempéries, mais estáveis), explica a preeminência (cerca de 73\%) do milho dentado também conhecido como milho amarelo (Reid Yellow Dent), nos EUA (Troyer, 2006, 2009).

A importância dos programas de melhoramento genético no desenvolvimento dos híbridos simples, de ciclo curto, alteraram o ideotipo dos cultivares de milho, produzindo uma planta de arquitetura mais compacta, melhor adaptada ao adensamento e mais eficiente em converter a fitomassa produzida à produção de grãos (Sangoi, 2010).

A diminuição da altura de plantas e da inserção de espigas, do tamanho do pendão, do número de folhas, da área foliar, bem como o aumento da uniformidade morfológica e fenológica, da força de dreno da espiga, da sincronia entre antese/espigamento e do índice da colheita, são características que contribuíram para a maior eficiência dos híbridos contemporâneos no aproveitamento de água, luz e nutrientes, principalmente em ambientes de alta competição intra-específica (Sangoi, 2010).

As plantas transgênicas são produtos obtidos a partir da modificação genética ou transformação de plantas, cuja criação envolve a inserção de DNA no genoma em uma ou mais sequências de pares de nucleotídeos, geralmente isoladas de uma ou mais espécies, para garantir a expressão gênica de um ou mais genes de interesse (Lerayer et al., 2006).

Os transgênicos derivam de cultivares convencionais por métodos de reprodução clássicos e são conhecidos como híbridos isogênicos. Desta forma, teoricamente, os híbridos isogênicos não devem apresentar diferenças na sua composição genética devido à tecnologia de DNA recombinante usada para criá-los, exceto o inserto de DNA transformante. Contudo, os eventos dos transgênicos podem interferir na adaptabilidade e estabilidade desses materiais (Prado et al., 2016).

Plantas geneticamente modificadas desenvolvidas para resistir ao ataque de insetos-praga podem, potencialmente, reduzir impactos negativos da agricultura ao ambiente em virtude da redução do uso de inseticidas químicos na cultura, com consequentes benefícios, como redução de poluição por resíduos tóxicos no ambiente (solo, água e alimentos ou matéria-prima), e aumento da segurança do trabalhador e possivelmente do controle biológico natural (Mendes, Boregas, Lopes, Waquil, \& Waquil, 2011).

O milho transgênico com o gene do Bt, recebeu genes específicos da bactéria Bacillus thuringiensis que promovem na planta a produção de uma proteína tóxica específica para determinados grupos de insetos. Entre os que estão sendo comercializados, destacam-se os que expressam as toxinas Cry 1A(b) e Cry 1F, com atividade sobre os lepidópteros, e o Cry3Bb1, para o controle de coleópteros (larvas de Diabrotica spp.) e mais recente o Cry1A.105 e Cry2Ab2, que representa uma segunda 
geração de milho transgênico resistente a insetos, pois produz simultaneamente duas proteínas derivadas do Bacillus thuringiensis, ativas contra lagartas-praga (Loguercio, Carneiro, \& Carneiro, 2002; Waquil, Villela, \& Foster, 2010).

A característica de tolerância ao glyphosate de híbridos de milho RRß (Roundup Ready®) possibilita que esse único herbicida seja utilizado com seletividade à cultura, mas de forma contrária, impossibilita o controle com esse herbicida de altas populações do próprio milho RRß, são plantas voluntárias (Goes Maciel et al., 2013).

Conforme Pereira Filho and Borghi (2016), na safra 2016/17 estiveram disponíveis para os produtores brasileiros 315 genótipos de milho, dos quais 214 materiais apresentam alguma tecnologia transgênica para o controle de pragas e/ou resistência ao glifosato. Este número de cultivares com eventos transgênicos representa $67,93 \%$ das cultivares que fizeram parte do mercado de milho para esta safra. Destes, 103 apresentam as tecnologias VT PRO (47 genótipos), VT PRO2 (32 genótipos) e VT PRO3 (24 genótipos). Os 101 genótipos que completam o levantamento não apresentam nenhuma tecnologia transgênica (convencionais) e representam $32,06 \%$ em relação ao total de materiais disponíveis. Desses materiais são $67,61 \%$ híbridos simples, 16,82\% híbridos triplos, 6,03\% híbridos duplos, 5,07\% variedades, 3,17\% híbridos simples modificados e 0,63\% são híbridos triplos modificados entre 315 materiais relacionados.

\section{FENOLOGIA DA CULTURA DO MILHO}

Todas as plantas de milho seguem um mesmo padrão de desenvolvimento. Entretanto, o intervalo entre os estádios e o número total de folhas desenvolvidas pode variar entre genótipos, ano agrícola, data de plantio e local. Os estádios vegetativos e reprodutivos da planta de milho (Figura 1) são: na Fase vegetativa (V), a partir da emergência $\left(V_{E}\right), V_{1}, V_{2}, V_{3}$ até $V_{n}$; em que (n) representa a última folha emitida antes do pendoamento $\left(\mathrm{V}_{\mathrm{T}}\right)$. Todas as folhas e espigas que a planta eventualmente irá produzir são formadas no V3. Pode-se dizer, portanto, que o estabelecimento do número máximo de grãos, ou a definição da produção potencial, estão sendo definidos nesse estádio (Magalhães \& Durães, 2006).

No estádio V5 (cinco folhas completamente desenvolvidas), tanto a iniciação das folhas como das espigas está completa e a iniciação do pendão já pode ser vista microscopicamente, na extremidade de formação do caule, logo abaixo da superfície do solo. $\mathrm{O}$ estádio $\mathrm{V}_{\mathrm{T}}$ inicia-se quando o último ramo do pendão está completamente visível. Durante esta fase, cada estádio é definido de acordo com a formação visível do colar na inserção da bainha da folha com o colmo. Assim, a primeira folha de cima para baixo, com o colar visível, é considerada completamente desenvolvida, sendo contada como tal. A fase reprodutiva $(\mathrm{R})$, tem início com o florescimento $\left(\mathrm{R}_{1}\right)$, compreendendo a visualização dos estilos - estigmas fora das brácteas. Os estádios posteriores são o de grão leitoso $\left(\mathrm{R}_{2}\right)$ de 10 a 14 dias após o florescimento, grão pastoso $\left(\mathrm{R}_{3}\right)$ de 18 a 22 dias após o florescimento, grão farináceo $\left(R_{4}\right)$ de 24 a 28 dias após o florescimento, grão farináceo duro $\left(R_{5}\right)$ de 35 a 42 dias após o florescimento e a maturidade fisiológica $\left(\mathrm{R}_{6}\right)$ de 55 a 65 dias após o florescimento (Magalhães \& Durães, 2006). 


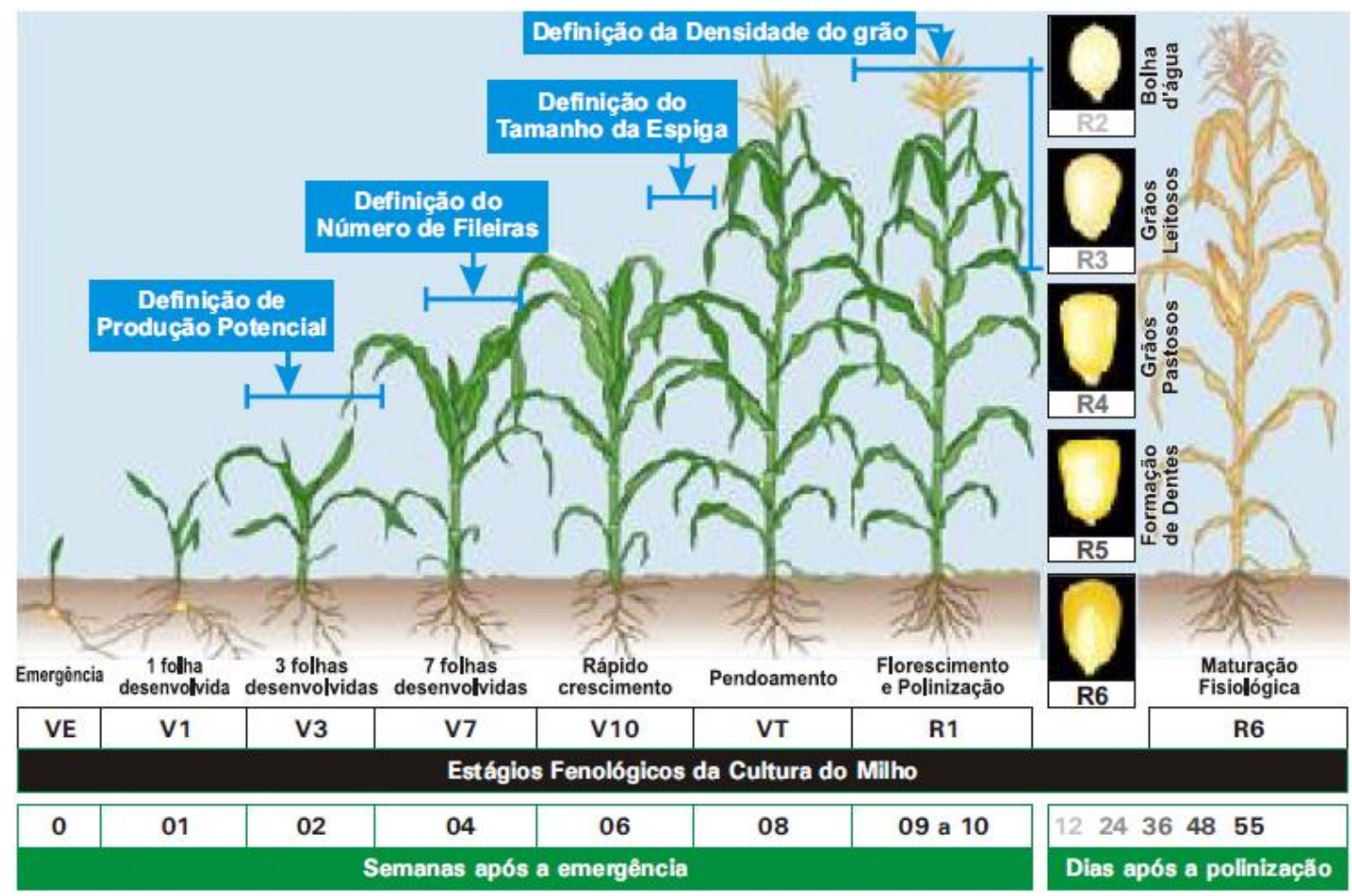

Figura 1- Fases de desenvolvimento da cultura do milho (Weismann, 2008).

\section{FATORES AMBIENTAIS QUE AFETAM A CULTURA DO MILHO}

Altos rendimentos de grãos de milho resultam do sucesso em se utilizar os fatores do ambiente com máxima eficiência, minimizando as causas adversas ao desenvolvimento das culturas. Esta complexa equação é dependente, principalmente, de três elementos meteorológicos: radiação solar, temperatura do ar e disponibilidade hídrica. A obtenção de elevado rendimento de grãos passa pela análise de cada um destes elementos, que interagem entre si (Rodrigues, Silva, \& Ferreira, 2011).

A interceptação da radiação fotossinteticamente ativa pelas plantas exerce grande influência sobre a sua performance quando outros fatores ambientais são favoráveis. Nos ecossistemas natural e cultivado, a atividade fotossintética das plantas resulta na conversão da energia solar em energia química, a qual é essencial para a produção vegetal, sendo a cultura do milho muito demandante da energia luminosa (Argenta \& Sangoi, 2001).

$\mathrm{O}$ milho pertence ao grupo de plantas com metabolismo fotossintético do tipo $\mathrm{C}_{4}$, que se caracteriza pelo elevado potencial produtivo. Entre as plantas $\mathrm{C}_{4}$, o milho está no grupo de espécies com maior eficiência de uso da radiação solar ou eficiência quântica, com valor médio entre 64,5 a 69 mmol mol $^{-1}$, enquanto outras espécies $\mathrm{C}_{4}$ apresentam valores em torno de 52,6 a $60,4 \mathrm{mmol} \mathrm{mol}^{-1}$ (Bergamaschi et al., 2004).

O milho responde muito bem a alta temperatura, desde que haja suficiente umidade de solo (a indicação do início da semeadura é quando o solo está com temperatura $\geq 16^{\circ} \mathrm{C}$ ) (Galon et al., 2011).

A disponibilidade hídrica é o fator que mais frequentemente limita a obtenção de elevado rendimento de grãos. O consumo diário de água durante o ciclo da cultura varia de 2 a $7 \mathrm{~mm}$, 
UNESUM-Ciencias: Revista Científica Multidisciplinaria ISSN 2602-8166

NITROGENIO E INOCULAÇÃO COM BACTÉRIAS PROMOTORAS DE CRESCIMENTO

dependendo do estádio e da demanda atmosférica. A maior exigência ocorre durante o pendoamento e espigamento (em torno de $7 \mathrm{~mm} /$ dia), quando a planta tem a maior área foliar (Westgate, 1994).

\section{CONCLUSIONES}

A cultura do milho é de muita importância social e económica no mundo.

O Nitrogênio é indispensável para o desenvolvimento produtivo da cultura do milho, sendo o nutriente mais limitante.

A aplicação de bactérias promotoras de crescimento para o incremento da produção do milho são uma alternativa para depender em menor quantidade dos fertilizantes químicos, estimulando a fixação biológica do nitrogênio.

La educación ambiental puede contribuir al manejo de los desechos sólidos y puede generar nuevos comportamientos, actitudes, valores y creencias que impulsen el desarrollo social, productivo y creador; como consecuencia puede ser el medio para el logro de nuevas relaciones entre los seres humanos y esencialmente en la formación de las nuevas generaciones, responsables del cuidado de este proceso en el futuro.

\section{REFERÉNCIAS BIBLIOGRÁFICAS}

Alfaia, S. S. (2006). Caracterização e distribuição das formas do nitrogênio orgânico em três solos da Amazônia Central. Acta Amazônia. vol.36, n.2, pp.135-140. http://dx.doi.org/10.1590/S0044-59672006000200001.

Alva, A., Paramasivam, S., Fares, A., Delgado, J., Mattos Jr, D., \& Sajwan, K. (2006). Nitrogen and irrigation management practices to improve nitrogen uptake efficiency and minimize leaching losses. Journal of Crop Improvement, 15(2), 369-420. https://doi.org/10.1300/J411v15n02_11.

Amado, T., Mielniczuk, J., \& Aita, C. (2002). Recomendação de adubação nitrogenada para o milho no RS e SC adaptada ao uso de culturas de cobertura do solo, sob sistema plantio direto. Revista Brasileira de Ciência do Solo, 26(1). http://dx.doi.org/10.1590/S0100-06832002000100025.

Amado, T., Mielniczuk, J., \& Fernandes, S. (2000). Leguminosas e adubação mineral como fontes de nitrogênio para o milho em sistemas de preparo do solo. Revista Brasileira de Ciência do Solo, 24(1), 179-189. http://dx.doi.org/10.1590/S0100-06832002000100025.

Andrade, A. C., Fonseca, D., Queiroz, D. S., Salgado, L. T., \& Cecon, P. R. (2003). Adubação nitrogenada e potássica em capim-elefante (Pennisetum purpureum Schum. cv. Napier). Ciência e Agrotecnologia, 27, 1643-1651.

Araújo, P. M., \& Nass, L. L. (2002). Caracterização e avaliação de populaçães de milho crioulo. Scientia Agricola, 59(3), 589-593. DOI: https://doi.org/10.1590/S0103-90162002000300027.

Araujo, S. (2008). Realidade e perspectivas para o uso de Azospirillum na cultura do milho. Rev. Inf. Agron, 122 , 4-6.

Argenta, G., \& Sangoi, L. (2001). Arranjo de plantas em milho: análise do estado-da-arte. Ciência Rural, 31(6).

Barros, J. F., \& Calado, J. G. (2014). A cultura do milho.

Bashan, Y., Puente, M. E., Rodriguez-Mendoza, M. N., Toledo, G., Holguin, G., Ferrera-Cerrato, R., \& Pedrin, S. (1995). Survival of Azospirillum brasilense in the Bulk Soil and Rhizosphere of 23 Soil Types. Applied and environmental Microbiology, 61(5), 1938-1945.

Bergamaschi, H., Dalmago, G. A., Bergonci, J. I., Bianchi, C. A. M., Müller, A. G., Comiran, F., \& Heckler, B. M. M. (2004). Distribuição hídrica no período crítico do milho e produção de grãos. Pesquisa Agropecuária Brasileira, 39(9), 831-839.

Bolaños, J., \& Edmeades, G. O. (1993). La fenologia del maiz. Retrieved from 
Freddy Zambrano Gavilanes, Diva Souza Andrade, Helder Rodrigues Silva...

Cella, D., \& de Lima Rossi, M. C. (2010). Análise do mercado de fertilizantes no Brasil. Revista Interface Tecnológica, $7(1), 10$.

Coelho, A. M. C. (2007). Manejo da adubação nitrogenada na cultura do milho: Embrapa Milho e Sorgo.

Cruz, J. C. C., Alvarenga, R., Novotny, E., Pereira Filho, I., Santana, D., Pereira, F., \& Hernani, L. (2010). Cultivo do milho: Embrapa Milho e Sorgo.

Cruz, S. C., Pereira, F. d. S., Santos, J. R., Albuquerque, A. \& Pereira, R. G. (2008). Adubação nitrogenada para o milho cultivado em sistema plantio direto, no Estado de Alagoas. Revista Brasileira de Engenharia Agrícola e Ambiental, 12(1), 62-68.

Demétrio, C. S., Fornasieri Filho, D., Cazetta, J. O., \& Cazetta, D. A. (2008). Desempenho de híbridos de milho submetidos a diferentes espaçamentos e densidades populacionais. Pesquisa Agropecuária Brasileira, 16911697.

Díaz-Zorita, M., Canigia, M. V. F., Bravo, O. Á., Berger, A., \& Satorre, E. H. (2015). Field Evaluation of Extensive Crops Inoculated with Azospirillum sp Handbook for Azospirillum (pp. 435-445): Springer. https://link.springer.com/chapter/10.1007/978-3-319-06542-7_24.

Döbereiner, J., Baldani, V. L. c. D., \& Baldani, J. I. (1995). Como isolar e identificar bactérias diazotróficas de plantas não-leguminosas: Embrapa SPI.

Dommergues, Y., Balandreau, J., \& Rinaudo, G. (1973). Non-symbiotic nitrogen fixation in the rhizospheres of rice, maize and different tropical grasses. Soil Biology and Biochemistry, 5(1), 83-89. https://doi.org/10.1016/0038-0717(73)90094-1.

Dörr de Quadros, P., Wurdig Roesch, L. F., Régis Ferreira da Silva, P., Macedo Vieira, V., Dinael Roehrs, D., \& de Oliveira Camargo, F. A. (2014). Desempenho agronômico a campo de híbridos de milho inoculados com Azospirillum. Revista Ceres, 61(2).

Dressler, R. L. (1953). The pre-Columbian cultivated plants of Mexico. Botanical Museum Leaflets, Harvard University, 16(6), 115-172.

Fallik, E., Okon, Y., \& Fischer, M. (1988). Growth response of maize roots to Azospirillum inoculation: effect of soil organic matter content, number of rhizosphere bacteria and timing of inoculation. Soil Biology and Biochemistry, 20(1), 45-49.

Fornasieri Filho, D. (2007). Manual da cultura do milho: Funep.

Franco, A., Balieiro, F. d. C., Siqueira, J., Moreira, F., Lopes, A., Guilherme, L., Carvalho, J. (1999). Fixação biológica de nitrogênio alternativa aos fertilizantes nitrogenados. Inter-relações fertilidade, biologia do solo e nutrição de plantas.

Freitas, F. d. O. (2002). As expansoes do milho-Zea mays, L.-para a América do Sul, baseado no resgate e estudo de DNA anciao de amostras arqueológicas. Embrapa Recursos Genéticos e Biotecnologia-Boletim de Pesquisa e Desenvolvimento (INFOTECA-E).

Fukami, J., Abrantes, J. L. F., del Cerro, P., Nogueira, M. A., Ollero, F. J., Megías, M., \& Hungria, M. (2017). Revealing strategies of quorum sensing in Azospirillum brasilense strains Ab-V5 and Ab-V6. Archives of Microbiology, 1-10. DOI: 10.1007/s00203-017-1422-x.

Fukami, J., Nogueira, M. A., Araujo, R. S., \& Hungria, M. (2016). Accessing inoculation methods of maize and wheat with Azospirillum brasilense. Amb Express, 6(1), 3. doi: 10.1186/s13568-015-0171-y.

Galindo, F. S., Teixeira Filho, M. C. M., Tarsitano, M. A. A., Buzetti, S., Santini, J. M. K., Ludkiewicz, M. G. Z., Arf, O. (2017). Economic analysis of corn inoculated with Azospirillum brasilense associated with nitrogen sources and doses. Semina: Ciências Agrárias, 38(4), 1749-1764. DOI: http://dx.doi.org/10.5433/16790359.2017v38n4p1749.

Galon, L., Tironi, S. P., da Rocha, A. A., Soares, E. R., Concenço, G., \& Alberto, C. M. (2011). Influência dos fatores abióticos na produtividade da cultura do milho. Revista Trópica: Ciências Agrárias e Biológicas, 4(3).

24 UNESUM-Ciencias. Publicación cuatrimestral. Vol. 3, Año 2019, No. 3 (Septiembre - Diciembre) 
UNESUM-Ciencias: Revista Científica Multidisciplinaria ISSN 2602-8166

NITROGENIO E INOCULAÇÃO COM BACTÉRIAS PROMOTORAS DE CRESCIMENTO

Goes Maciel, C. D., Zobiole, L. H. S., Souza, J. I., Hirooka, E., Lima, L. G. N. V., Soares, C. R. B., Helvig, E. O. (2013). Eficácia do herbicida Haloxyfop R (GR-142) isolado e associado ao 2, 4-D no controle de híbridos de milho RR voluntário. Revista Brasileira de Herbicidas, 12(2), 112-123. https://doi.org/10.7824/rbh.v12i2.244.

Goloubinoff, P., Pääbo, S., \& Wilson, A. C. (1993). Evolution of maize inferred from sequence diversity of an Adh2 gene segment from archaeological specimens. Proceedings of the National Academy of Sciences, 90(5), 19972001.

Hawkesford, M., Horst, W., Kichey, T. M. R., Schjørring, J. K., Møller, I. S., \& White, P. (2012). Functions of macronutrients Marschers's Mineral Nutrition of Higher Plants (pp. 135-189): Elsevier Science. https://doi.org/10.1016/C2009-0-63043-9.

Hungria, Franchini, J., Campo, R., \& Graham, P. (2005). The importance of nitrogen fixation to soybean cropping in South America Nitrogen fixation in agriculture, forestry, ecology, and the environment (pp. 25-42): Springer.

Hungria, M. (2011). Inoculação com Azospirillum brasilense: inovação em rendimento a baixo custo: Embrapa Soja.

Hungria, M., Campo, R. J., \& Mendes, I. D. (2001). Fixação biológica do nitrogênio na cultura da soja: Embrapa Soja; Brasília, DF: Embrapa Cerrados.

Hungria, M., Campo, R. J., Souza, E. M., \& Pedrosa, F. O. (2010). Inoculation with selected strains of Azospirillum brasilense and A. lipoferum improves yields of maize and wheat in Brazil. Plant and Soil, 331(1-2), 413-425. https://doi.org/10.1007/s11104-009-0262-0.

Hungria, M., Loureiro, M., Mendes, I., Campo, R., \& Graham, P. (2005). Inoculant preparation, production and application Nitrogen fixation in agriculture, forestry, ecology, and the environment (pp. 223-253): Springer. Doi: 10.1007/1-4020-3544-6.

Jaffe, D. A. (1992). 12 The Nitrogen Cycle. International Geophysics, 50, 263-284.

Kaneko, F. H., Sabundjian, M. T., Arf, O., Leal, A. J. F., Carneiro, L. F., \& Paulino, H. B. (2016). Análise econômica do milho em função da inoculação com Azospirillum, fontes e doses de $\mathrm{N}$ em cobertura. Revista Brasileira de Milho e Sorgo, 15(2), 202-216. DOI: http://dx.doi.org/10.18512/1980-6477/rbms.v15n2p202-216.

Kole, C. (2007). Genome mapping and molecular breeding in plants (Vol. 1): Springer Heidelberg. https://link.springer.com/content/pdf/bfm\%3A978-3-540-34389-9\%2F1.pdf.

Lerayer, R., Paterniani, E., Silveira, J., Menossi, M., Oda, L., \& Di Ciero, L. (2006). Avaliação de impactos do milho geneticamente modificado. Conselho de Informações Sobre Biotecnologia $(C I B)$ Disponível em: $<$ Disponível em: http://www. cib. org. br/ctnbio/avaliacao_de_impactos_milho_CTNBIOl.pdf>. Acessado em, 17.

Loguercio, L. L., Carneiro, N. P., \& Carneiro, A. A. (2002). Milho BT: alternativa biotecnológica para controle biológico de insetos-praga. Embrapa Milho e Sorgo-Artigo em periódico indexado (ALICE).

Longhini, V. Z., Souza, W. C., Andreotti, M., Soares, N. d. A., \& Costa, N. R. (2016). Inoculation of diazotrophic bacteria and nitrogen fertilization in topdressing in irrigated corn. Revista Caatinga, 29(2), 338-347. http://dx.doi.org/10.1590/1983-21252016v29n210rc.

Magalhães, P., \& Durães, F. (2006). Fisiologia da produção de milho. Embrapa Milho e Sorgo. Circular Técnica.

Magalhães, P. C. (2002). Fisiologia do milho. CEP, 35701, 970.

Malusá, E., Sas-Paszt, L., \& Ciesielska, J. (2012). Technologies for beneficial microorganisms inocula used as biofertilizers. The scientific world journal.

Mangelsdorf, P. C. (1974). Corn. Its origin, evolution and improvement: Belknap Press of Harvard University Press. doi: $10.1100 / 2012 / 491206$.

Marks, B. B., Megías, M., Ollero, F. J., Nogueira, M. A., Araujo, R. S., \& Hungria, M. (2015). Maize growth promotion by inoculation with Azospirillum brasilense and metabolites of Rhizobium tropici enriched on lipochitooligosaccharides (LCOs). Amb Express, 5(1), 71. doi: 10.1186/s13568-015-0154-z. 
Freddy Zambrano Gavilanes, Diva Souza Andrade, Helder Rodrigues Silva...

Meinicke Nascimento, F., Bicudo, S. J., Lança Rodrigues, J. G., Barros Furtado, M., \& Campos, S. (2011). Produtividade de genótipos de milho em resposta à época de semeadura. Revista Ceres, 58(2). http://dx.doi.org/10.1590/S0034-737X2011000200010.

Mendes, S. M., Boregas, K. G. B., Lopes, M. E., Waquil, M. S., \& Waquil, J. M. (2011). Respostas da lagarta-do-cartucho a milho geneticamente modificado expressando a toxina Cry 1A (b). Pesquisa Agropecuária Brasileira, 46(3), 239-244. http://dx.doi.org/10.1590/S0100-204X2011000300003.

Ohland, R. A. A., Souza, L. d., Hernani, L. C., Marchetti, M. E., \& Gonçalves, M. C. (2005). Culturas de cobertura do solo e adubação nitrogenada no milho em plantio direto. Ciência e Agrotecnologia, 29(3), 538-544. http://dx.doi.org/10.1590/S1413-70542005000300005.

Peixoto, C. d. M. (2014). O milho no Brasil, sua importância e evolução. Seed News.

Pereira Filho, I. A., \& Borghi, E. (2016). Mercado de sementes de milho no Brasil: safra 2016/2017. Embrapa Milho e Sorgo-Documentos (INFOTECA-E).

Prado, W. S., Estevão, W. L., Maeda, A. K. M., Carlesso, A., Gonçalves, M. C., \& Davide, L. M. C. (2016). Agronomic performance of transgenic and isogenic corn hybrids in the state of Mato Grosso do Sul1. Revista Ceres, 63(6), 796-806. http://dx.doi.org/10.1590/0034-737x201663060008.

Raij, B. (1996). Recomendações de adubação e calagem para o Estado de São Paulo: IAC Campinas.

Rodrigues, L., Silva, P., \& FERREIRA, P. (2011). Indicações técnicas para o cultivo do milho e do sorgo no Rio Grande do Sul: safras 2011/2012 e 2012/2013. Reunião técnica anual de milho, 56.

Sangoi, L. (2010). Evolução Genética e Morfo-Fisiológica de Cultivares de Milho, Eficiência Nutricional e Interações com o Ambiente.

Santos, J. d. S., Viana, T. d. O., Jesus, C. M. d., Baldani, V. L. D., \& Ferreira, J. S. (2015). Inoculation and isolation of plant growth-promoting bacteria in maize grown in Vitória da Conquista, Bahia, Brazil. Revista Brasileira de Ciência do Solo, 39(1), 78-85. http://dx.doi.org/10.1590/01000683rbcs20150725.

Severino, F., Carvalho, S., \& Christoffoleti, P. (2006). Interferências mútuas entre a cultura do milho, espécies forrageiras e plantas daninhas em um sistema de consórcio. II-Implicações sobre as espécies forrageiras. Planta daninha, 24(1), 45-52. http://dx.doi.org/10.1590/S0100-83582006000100006.

Smith, R. (1992). Legume inoculant formulation and application. Canadian Journal of Microbiology, 38(6), 485-492. https://doi.org/10.1139/m92-080.

Souza Moreira, F. M., Silva, K., Nóbrega, R. S. A., \& Carvalho, F. (2010). Bactérias diazotróficas associativas: diversidade, ecologia e potencial de aplicações. Comunicata Scientiae, 1(2), 74-100.

Trivelin, P. C. O., de Oliveira, M. W., Vitti, A. C., de Castro Gava, G. J., \& Bendassolli, J. A. (2002). Perdas do nitrogênio da uréia no sistema solo-planta em dois ciclos de cana-de-açúcar. Pesquisa Agropecuária Brasileira, 37(2), 193-201. http://dx.doi.org/10.1590/S0100-204X2002000200011.

Troyer, A. F. (2006). Adaptedness and heterosis in corn and mule hybrids. Crop Science, 46(2), 528-543.

Troyer, A. F. (2009). Development of hybrid corn and the seed corn industry. Handbook of maize, 87-114. https://doi.org/10.1007/978-0-387-77863-1_5.

Waquil, J. M., Villela, F. M. F., \& Foster, J. E. (2010). Resistência do milho (Zea mays L.) transgênico (Bt) à lagartado-cartucho, Spodoptera frugiperda (Smith)(Lepidoptera: Noctuidae). Revista Brasileira de Milho e Sorgo, 1(03). http://dx.doi.org/10.18512/1980-6477/rbms.v1n03p\%25p.

Weismann, M. (2008). Fases de desenvolvimento da cultura do milho. Tecnologias e produção: Milho safrinha e culturas de inverno. Maracaju: Fundação MS, 31-38.

Westgate, M. E. (1994). Seed formation in maize during drought. Physiology and determination of crop yield(physiologyandde), 361-364.

Wiethölter, D. P. S. (2004). Épocas e métodos de aplicação de nitrogênio em milho cultivado no sistema plantio direto. Ciência Rural, 34(4). http://dx.doi.org/10.1590/S0103-84782004000400007. 